\title{
Unequal Associations between Educational Attainment and Occupational Stress across Racial and Ethnic Groups
}

\author{
Shervin Assari 1,*(D) and Mohsen Bazargan 1,2 \\ 1 Departments of Family Medicine, College of Medicine, Charles R Drew University of Medicine and Science, \\ Los Angeles, CA 90059, USA; Mohsenbazargan@cdrewu.edu \\ 2 Departments of Family Medicine, University of California, Los Angeles (UCLA), Los Angeles, CA 90095, USA \\ * Correspondence: assari@umich.edu
}

Received: 25 August 2019; Accepted: 17 September 2019; Published: 21 September 2019

check for updates

\begin{abstract}
Background: Although other mechanisms are also involved, at least one reason high educational attainment (EA) is associated with better health is lower employment stress in individuals with high EA. Minorities' Diminished Returns, however, refer to the smaller protective health effects of EA for racial- and ethnic-minority individuals, particularly African Americans (AAs) and Hispanics, as compared to Whites. We are, however, not aware of many studies that have explored differential associations between EA and work-related stress across racial and ethnic groups. Aims: We aimed to compare racial and ethnic groups for the association between EA and occupational stress in a national sample of American adults. Methods: The National Health Interview Survey (NHIS 2015), a cross-sectional survey, included 15,726 employed adults. Educational attainment was the independent variable. Occupational stress was the outcome. Race and ethnicity were the moderators. Age, gender, number of jobs, and years in the job were the covariates. Results: Overall, higher EA was associated with lower levels of occupational stress. Race and ethnicity both interacted with EA, suggesting that the association between high EA and reduced occupational stress is systemically smaller for AAs and Hispanics than it is for Whites. Conclusions: In the United States, race and ethnicity limit the health gains that follow EA. While EA helps individuals avoid environmental risk factors, such as occupational stress, this is more valid for non-Hispanic Whites than AAs and Hispanics. The result is additional physical and mental health risks in highly educated AAs and Hispanics. The results are important, given racial and ethnic minorities are the largest growing section of the US population. We should not assume that EA is similarly protective across all racial and ethnic groups. In this context, EA may increase, rather than reduce, health disparities.
\end{abstract}

Keywords: population groups; ethnicity; race; Hispanics; Latinos; Whites; Blacks; African Americans; socioeconomic position; socioeconomic status; education; stress; occupational stress; work; employment

\section{Introduction}

According to the Minorities' Diminished Returns (MDRs) theory [1-5], at least some of the racial/ethnic disparities are due to the "less than expected" protective effects of socioeconomic status (SES) indicators, such as educational attainment (EA) [1,6-8]. The MDRs theory suggests that (a) racial/ethnic health disparities are not all due to SES gaps but are also due to differential health gains that follow high SES for African American (AA) and Hispanic populations, (b) the racial and ethnic health inequalities tend to widen at higher SES levels, and (c) there is a need to address racial/ethnic disparities across all SES levels [1-3].

Some evidence suggests that MDRs hold for a wide range of health domains. Similar results are shown for a wide range of physical [9-12] and mental health [13,14] outcomes, meaning that high-SES 
AAs and Hispanics tend to have worse health when compared to high-SES Whites [13,15-17]. Very few studies, however, have explored the MDRs of EA on occupation characteristics. In one study, EA better reduced secondhand-smoke exposure at workplaces for Whites than at workplaces for AAs [18].

The US labor market is a dual system. One system is composed of low-stress, high-pay, prestigious jobs. Another system is composed of high-demand, high-stress, low-pay jobs. The US labor market is known to discriminate against racial and ethnic minorities and employ the majority of racial and ethnic minorities in the lower-tier jobs. That is, the labor market, similar to the broader society, tends to marginalize AAs and Hispanics [10,19]. A large body of research has shown that identical $\mathrm{CVs}$ and resumes generate very different outcomes for people, simply based on the racial and ethnic names [20]. As a result, highly educated AAs and Hispanics are less likely to secure high-quality occupations. As a result, highly educated AAs and Hispanics still work in jobs that are high in exposure to a wide range of stressors, toxicants, and undesired conditions [18,19]. One study was published recently, showing that highly educated AAs and Hispanics are more likely to be exposed to environmental exposures, such as secondhand smoke, than highly educated Whites [18]. In addition to the labor-market discrimination, residential segregation also plays a role. AAs and Hispanics are more likely to live in areas with poor job opportunities. Thus, highly educated AAs and Hispanics have a lower chance of accessing good occupations, even in the absence of labor-market discrimination $[18,19]$. Finally, the education is of lower quality for racial and ethnic minority groups. This may also result in differential association between educational attainment and occupation quality of highly educated AAs and Hispanics. All of these possibilities potentially explain the MDRs of educational attainment on health $[1,6,7,18,21]$.

Aims

In response to the gap in the literature on the contribution of occupational stress as an explanatory mechanism for MDRs, we conducted a study to explore race and ethnic variations in the association between EA and occupational stress in employed American adults. We had two hypotheses.

Hypothesis 1. We expected an inverse association between EA and occupational stress in the overall sample.

Hypothesis 2. We expected the inverse association between EA and occupational stress to be smaller for AAs and Hispanics than for non-Hispanic Whites.

\section{Materials and Methods}

\subsection{Design and Settings}

This is a secondary analysis of the 2015 National Health Interview Survey (NHIS) data, the main national health surveys of Americans, which are funded and conducted by the CDC [22]. The NHIS participants were eligible if they were (1) civilians, (2) non-institutionalized, (3) part of the US population, and (4) 18+ years of age. The NHIS sampling was a multistage, clustered, stratified probability sample. Although the NHIS 2015 includes 33,672 adults (from all races and ethnicities and including employed and non-employed), this analysis was limited to adults who were either White or AA and were employed. Thus, only 15,726 individuals entered our analysis.

\subsection{Study Variables}

The study variables included demographics (age and gender), race, ethnicity, EA (SES), region, years of employment, number of occupations, and occupational stress, which were all measured at an individual level. Race and ethnicity were self-identified and included AAs versus Whites and Hispanics versus non-Hispanics. Demographic Characteristics included age and gender. Age was a continuous measure, and gender was a dichotomous measure (male 1, female 0). Having more than one job was a dichotomous variable. Participants were asked if they were working at more than one 
job. Educational Attainment was a continuous measure, varying from 0 to 24 years. Marital Status was $1=$ married versus $0=$ any other status (never married, widowed, separated, divorced, and living with a partner). Region was operationalized as three binary variables: (1) the Northeast, (2) the Midwest, and (3) the South. The reference group was the West.

The outcome in this study was occupational stress, which was measured using the following items: (1) job interferes with personal or family life; (2) subject does not have enough time to get job done; (3) job does not allow for making decisions; (4) subject does not have support from supervisor when necessary; (5) workplace is unsafe; (6) employee health/safety is not important to management; (7) frequency of harassment at work; (8) frequency of job-required repeated activities, like lifting and pulling; and (9) frequency of job requiring standing or walking. Item responses ranged from 1 to 5 , with 5 reflecting more stress. Our overall occupational stress score ranged from 1 to 5 , which was average of all nine above items. (Cronbach alpha $=0.63$ )

This study measure was not a standardized measure but was conceptualized based on the following theoretical frameworks: minority stress theory, dual job market theory, job demands theory, and effort-reward imbalance. Minority stress theory explains that due to racism, discrimination, and prejudice, minority groups experience and perceive more stress than the mainstream populations, and the labor market is not an exception to this rule. Thus, AAs experience more harassment and discrimination in the workplace [23]. Based on the effort-reward imbalance, we can argue that non-Whites are rewarded less for the same amount of effort they put into their work. In this view, the economic and noneconomic return for occupational investment would be smaller for the members of the minority than for the majority groups [24]. That is, being a discriminatory system, the labor market tends to undervalue non-Whites' contributions to the workforce. Job demands theory suggests that perceived occupational stress is high when the job is demanding and employees do not have access to the support that they need to successfully complete their occupational tasks. Such demands may be higher, and the provided support may be lower, in the occupations that AAs enter. In these jobs, the individuals perceive lower control over life and feel overburdened [25,26]. The dual job market theory argues that AAs and Hispanics enter second-tier jobs that are determined by a high workload, high stress, low benefits, and minimal pay. Thus, race and ethnicity impact occupational stress through types of occupations that each racial and ethnic group occupies [27-29].

\subsection{Data Analytical Plan}

We analyzed the data using SPSS 23.0 (IBM Corporation, Armonk, NY, USA), which enabled us to accommodate survey weights. First, we examined the distribution of our variables. Then, we used the Pearson correlation test to estimate univariate correlations between the study variables. To perform our multivariable analysis, linear regressions were used. Before running the models, we tested the assumptions and requirements, such as linear distribution of errors and no collinearity between independent variables. We ran models in the pooled sample, both with and without interaction terms between race and ethnicity with EA.

\subsection{Ethics}

According to the NIH and Charles R Drew University of Medicine and Science (CDU) definition of human subjects research, this study was found to be a non-human subject research, which is except from a Ethics Review Board (IRB) review. We used the NIH decision tool available here: https://grants.nih.gov/policy/humansubjects/research.htm. The NHIS main study protocol, however, was fully reviewed and approved by the Research Ethics Review Board (IRB) of the National Center for Health Statistics, CDC. All participants signed written informed consent. Participants were reminded that they had the right not to participate in the study, to cancel their participation at any moment, or to decline to answer any questions that they wished not to answer. 


\section{Results}

\subsection{Descriptive Statistics}

Table 1 shows the descriptive statistics of our participants. This analysis included 15,726 American adults. This number was composed of Whites $(13,322,84.7 \%)$ or AAs $(2398,15.3 \%)$. This sample was mostly non-Hispanic $(13,741,87.6 \%)$ and only 1951 individuals $(12.4 \%)$ were Hispanic. The mean age of our participants was $43.4(\mathrm{SD}=14.2)$ years. The mean EA of the participants was 15.8 years $(\mathrm{SD}=2.8$ years).

Table 1. Descriptive statistics.

\begin{tabular}{lcc}
\hline & $n$ & $\%$ \\
\hline Race & & \\
$\quad$ White & 13,322 & 84.7 \\
$\quad$ African American (AA) & 2398 & 15.3 \\
\hline Ethnicity & & \\
$\quad$ Non-Hispanic & 13,741 & 87.6 \\
$\quad$ Hispanic & 1951 & 12.4 \\
\hline Gender & & \\
Female & 7955 & 50.6 \\
$\quad$ Male & 7765 & 49.4 \\
\hline Region & & \\
$\quad$ Northeast & 2584 & 16.4 \\
$\quad$ Midwest & 3761 & 23.9 \\
$\quad$ South & 5600 & 35.6 \\
$\quad$ West & 3781 & 24.1 \\
\hline Marital Status & & \\
Other & 8429 & 53.6 \\
$\quad$ Married & 7291 & 46.4 \\
\hline Working at More than One Job & & \\
$\quad$ No & 14,271 & 90.9 \\
$\quad$ Yes & 1431 & 9.1 \\
\hline$\quad$ Mean & $S D$ \\
Age (Years) & 43.44 & 14.20 \\
Educational Attainment (EA) & 15.81 & 2.78 \\
Income & 6.86 & 2.92 \\
Occupational Stress & 1.80 & 0.45 \\
\hline
\end{tabular}

\subsection{Bivariate Analysis}

Table 2 shows zero order (unadjusted) correlations between the study variables. We found positive correlations between race (AAs) and ethnicity (Hispanics) with occupational stress. Age, EA, and income were negatively correlated with occupational stress (Table 2). 
Table 2. Correlation Matrix.

\begin{tabular}{|c|c|c|c|c|c|c|c|c|c|c|c|c|c|}
\hline & 1 & 2 & 3 & 4 & 5 & 6 & 7 & 8 & 9 & 10 & 11 & 12 & 13 \\
\hline 1 Race (AAs) & 1 & $-0.13^{* *}$ & $-0.03^{* *}$ & $-0.07^{* *}$ & -0.01 & $-0.02 *$ & $-0.07^{* *}$ & $0.21^{* *}$ & $-0.15^{* *}$ & 0.01 & $-0.06^{* *}$ & $-0.10^{* *}$ & $0.19^{* *}$ \\
\hline 2 Ethnicity (Hispanics) & & 1 & $-0.10^{* *}$ & $0.03 * *$ & 0.00 & $-0.04 * *$ & $-0.12 * *$ & $0.07^{* *}$ & -0.01 & $-0.04 * *$ & $-0.28^{* *}$ & $-0.14^{* *}$ & $0.05 * *$ \\
\hline 3 Age & & & 1 & 0.00 & $-0.06^{* *}$ & $0.06^{* *}$ & $-0.02 *$ & $-0.03 * *$ & $0.18^{* *}$ & $-0.02 * *$ & $0.04 * *$ & $0.19 * *$ & $-0.09^{* *}$ \\
\hline 4 Gender Male & & & & 1 & -0.01 & -0.01 & 0.01 & $-0.03 * *$ & $0.07^{* *}$ & $-0.02 *$ & $-0.07^{* *}$ & $0.19 * *$ & $0.04^{* *}$ \\
\hline 5 LGB & & & & & 1 & 0.01 & $-0.02 *$ & 0.01 & $-0.11 * *$ & 0.01 & $0.04 * *$ & -0.01 & 0.00 \\
\hline 6 Region-Northeast & & & & & & 1 & $-0.25 * *$ & $-0.33 * *$ & 0.01 & 0.01 & $0.05 * *$ & $0.05 * *$ & -0.01 \\
\hline 7 Region-Midwest & & & & & & & 1 & $-0.42 * *$ & 0.00 & $0.03^{* *}$ & 0.01 & $-0.03 * *$ & 0.00 \\
\hline 8 Region-South & & & & & & & & 1 & $-0.02 * *$ & $-0.04 * *$ & $-0.04^{* *}$ & $-0.04^{* *}$ & 0.01 \\
\hline 9 Married & & & & & & & & & 1 & $-0.04^{* *}$ & $0.09 * *$ & $0.20 * *$ & $-0.08^{* *}$ \\
\hline 10 Has One Job & & & & & & & & & & 1 & $0.07^{* *}$ & -0.01 & $0.02 * *$ \\
\hline 11 Education Attainment (EA) & & & & & & & & & & & 1 & $0.37 * *$ & $-0.23 * *$ \\
\hline 12 Income & & & & & & & & & & & & 1 & $-0.16^{* *}$ \\
\hline 13 Occupational Stress & & & & & & & & & & & & & 1 \\
\hline
\end{tabular}

Notes: Source the National Health Interview Survey (NHIS 2015); CI: confidence interval; SE: standard error; LGB: Lesbian, gay, and bisexual; AA: African American; ${ }^{* *} p<0.05 .{ }^{* *} p<0.01$. 


\subsection{Multivariable Analysis}

Table 3 shows the summary of the results of two linear regression models, with EA as the independent variable and occupational stress as the dependent variable. These models were run in the overall sample. Model 1 focused on the main effects of EA, race, ethnicity, and covariates. Model 2 had those variables in addition to interaction terms between race and ethnicity with EA. Based on Model 1, high EA reduced occupational stress; however, based on Model 2, this association was weaker for AAs and Hispanics than it was for Whites and non-Hispanics (Table 3).

Table 3. Two linear regressions with occupational stress as the outcome.

\begin{tabular}{|c|c|c|c|c|c|c|}
\hline & Standardized Coefficients & B & SE & $95 \% \mathrm{CI}$ & & $p$ \\
\hline \multicolumn{7}{|l|}{ Model 1 (Main Effects) } \\
\hline Race (AAs) & 0.19 & 0.24 & 0.01 & 0.21 & 0.26 & $<0.000$ \\
\hline Ethnicity (Hispanics) & 0.00 & 0.00 & 0.01 & -0.02 & 0.03 & 0.754 \\
\hline Age & -0.06 & 0.00 & 0.00 & 0.00 & 0.00 & $<0.000$ \\
\hline Gender Male & 0.05 & 0.05 & 0.01 & 0.03 & 0.06 & $<0.000$ \\
\hline LGB & 0.01 & 0.02 & 0.02 & -0.02 & 0.06 & 0.268 \\
\hline \multicolumn{7}{|l|}{ Region } \\
\hline Northeast & 0.00 & 0.00 & 0.01 & -0.02 & 0.03 & 0.915 \\
\hline Midwest & 0.00 & 0.00 & 0.01 & -0.02 & 0.02 & 0.806 \\
\hline South & -0.03 & -0.03 & 0.01 & -0.05 & -0.01 & 0.004 \\
\hline Married & -0.01 & -0.01 & 0.01 & -0.03 & 0.01 & 0.203 \\
\hline Has One Job & 0.03 & 0.05 & 0.01 & 0.02 & 0.07 & $<0.000$ \\
\hline Education Attainment (EA) & -0.19 & -0.03 & 0.00 & -0.03 & -0.03 & $<0.000$ \\
\hline Income & -0.07 & -0.01 & 0.00 & -0.01 & -0.01 & $<0.000$ \\
\hline Constant & & 2.41 & 0.03 & 2.36 & 2.47 & $<0.000$ \\
\hline \multicolumn{7}{|l|}{ Model 2 (M1 + Interactions) } \\
\hline Race (AA) & 0.03 & 0.03 & 0.07 & -0.10 & 0.16 & 0.627 \\
\hline Ethnicity (Hispanic) & -0.13 & -0.18 & 0.05 & -0.28 & -0.09 & $<0.000$ \\
\hline Age & -0.06 & 0.00 & 0.00 & 0.00 & 0.00 & $<0.000$ \\
\hline Gender Male & 0.05 & 0.05 & 0.01 & 0.03 & 0.06 & $<0.000$ \\
\hline LGB & 0.01 & 0.02 & 0.02 & -0.02 & 0.06 & 0.256 \\
\hline \multicolumn{7}{|l|}{ Region } \\
\hline \multicolumn{7}{|l|}{ Yees } \\
\hline Northeast & 0.00 & 0.00 & 0.01 & -0.02 & 0.03 & 0.893 \\
\hline Midwest & 0.00 & 0.00 & 0.01 & -0.02 & 0.02 & 0.920 \\
\hline South & -0.03 & -0.03 & 0.01 & -0.05 & -0.01 & 0.005 \\
\hline Married & -0.01 & -0.01 & 0.01 & -0.02 & 0.01 & 0.263 \\
\hline Has One Job & 0.03 & 0.05 & 0.01 & 0.02 & 0.07 & $<0.000$ \\
\hline Education Attainment (EA) & -0.23 & -0.04 & 0.00 & -0.04 & -0.03 & $<0.000$ \\
\hline Income & -0.06 & -0.01 & 0.00 & -0.01 & -0.01 & $<0.000$ \\
\hline Race (AAs) $\times$ EA & 0.16 & 0.01 & 0.00 & 0.00 & 0.02 & 0.002 \\
\hline Ethnicity $($ Hispanics) $\times$ EA & 0.13 & 0.01 & 0.00 & 0.01 & 0.02 & $<0.000$ \\
\hline Constant & & 2.50 & 0.03 & 2.43 & 2.57 & $<0.000$ \\
\hline
\end{tabular}

Notes: Source the National Health Interview Survey (NHIS 2015); CI: confidence interval; SE: standard error; LGB: Lesbian, gay, and bisexual; AA: African American.

\section{Discussion}

Two main findings were observed. First, in general, a high EA was associated with less occupational stress. Second, this association was a function of race and ethnicity. The smaller inverse association between a high EA and reduced occupational stress in non-Whites offers a potential explanation for the MDRs of educational attainment, employment, and even income on the health of AAs and Hispanics.

The results of this study can also be understood as being in line with other empirical studies in the field $[30,31]$. In such studies, the main findings demonstrate consistent associations between higher education and lower levels of work stress in all countries. The strength of this association, however, varies across countries and is comparatively small in countries offering pronounced 'integrative' policies, in terms of high investments into measures of an active labor market policy and high 
participation rates in lifelong learning activities [32]. The results pointed to different types of policies that may help to reduce educational differences in work stress, in particular policies supporting those who are disadvantaged in the labor market. Overall political climate [33-36] and welfare state [37-39] also impact occupational stress across racial and ethnic groups.

The results are important because national and local policy regulations can be implemented to minimize the MDRs of EA on occupational stress for AAs and Hispanics. This is because occupational stress can be manipulated by policies such as affirmative action, minimum pay, and benefits associated with jobs. The elimination of discrimination in the labor market can equalize the stressful conditions of occupations for racial groups so that we can expect Blacks, Hispanics, and Whites to experience the same level of occupational stress at each socioeconomic level. These policy changes may reduce inequalities that are due to the stressful work of AAs and Hispanics.

The results are similar to another recent study that EA better reduced any and daily secondhand-smoke exposure at work for Whites than it did for AAs and Hispanics [18]. Thus, occupational and employment conditions may be one of the mechanisms in which EA shows smaller health effects for AAs and Hispanics than for Whites, as shown by several previous studies $[1,7,8,15,18,21,40]$. The results may also explain why employment gives a greater life expectancy to White men and women and almost no additional years of life expectancy to AA men. In another study, for AAs, an increase in EA meant a higher likelihood of working in a White workplace and having more White coworkers. Such an increase in exposure to Whites in the workplace was associated with an increase in received discrimination. We can now understand why EA [1,7,8,15,18,21,40], generated income [9,14,41], and employment [10,42] bring vastly different health effects to Whites and AAs.

The MDRs literature has shown that EA and income have weaker effects on reducing the risk of obesity, chronic disease, depression, self-rated health, and mortality for AAs compared to Whites $[13,15,43,44]$. That is, highly educated AAs are more obese [9], more depressed [14,45], have more CMCs [46], report worse health [19,47], and die earlier [48] when compared to highly educated Whites. The current results suggest that at least some of the MDRs are because highly educated AAs have higher occupational stress than whites. That is, highly educated AAs enter jobs that are associated with higher levels of stress.

EA does not lower occupational stress for AAs. That means that highly educated AAs still have high levels of job stress. As a result, high-SES AAs and Hispanics, as described by the MDRs theory [1-3], would show a worse-than-expected health status [1,7,8,15,18,21,40]. Obesity [12], depression [14], anxiety [49], self-rated health [47], and chronic disease [46] are all worse than expected in highly educated AAs than in Whites. Similar patterns for various health outcomes suggest that the processes that cause MDRs are upstream and impact almost all health outcomes. At least some of the processes that cause racial and ethnic health disparities happen in the society, rather than the health-care system [50-54].

High occupational stress of highly educated AAs may be due to multiple factors. Given the existing residential segregation, highly educated AAs do not have access to high-paying, low-stress jobs. In addition to job segregation, due to labor-market discrimination, highly educated AAs and Hispanics enter the types of jobs that pay less and have more stress. Residential segregation also reduces the quality of education in the AA and Hispanic communities. As the quality of education is a determinant of the quality of occupation, AAs enter worse jobs than Whites.

As a result, there is a need to reduce MDRs through multiple policies. The solution should not be limited to equalizing SES, such as EA and employment, but also qualitatively reducing the gap between the education and employment of racial and ethnic groups. Higher enforcement of antidiscrimination laws should apply to the sectors of the society that are involved in EA and employment. At the same time, AA individuals should be helped to secure higher-paying, lower-stress jobs. Such solutions to MDRs may be needed to eliminate health disparities. 


\subsection{Implications}

The results may help create policies and programs that improve structural and institutional barriers in the lives of AAs and Hispanics. There is a need for bold, innovative social and economic policies. Policy makers may run an "impact analysis" of their employment and labor policies, not just on the overall population but also on how such policies help generate or close the racial and ethnic gaps in health. Enforcing the existing antidiscrimination laws and penalizing the section of the labor market that does not adhere to antidiscrimination laws may equalize employment of racial and ethnic groups. Policies and programs are also needed to help AAs and Hispanics secure better jobs.

\subsection{Future Research}

There is a need to conduct more research on the solutions to occupational stress in AA and Latino communities. We also do not know what health problems, both mental and physical, are shaped by the additional occupational stress of the AA community. We also do not know how we can equalize race/ethnicity in terms of occupational stress.

It is also necessary to verify these results through qualitative research conducted on a small representative sample of minority groups. Thus, further investigation of the causes of these results, using various methods, is needed. There is also a need to study the implications that the results of this research will have on policy makers in the labor market.

\subsection{Limitations}

This study had some methodological limitations. The cross-sectional design of our data does not allow for causal inferences. The outcome was measured using single-item measure. We only measured workplace secondhand exposure. The sample size was imbalanced across race and ethnic groups. Many SES indicators, such as income, employment, and marital status were missing. This study did not measure health and depression. This study was limited to individual-level SES, and future research could also include area-level SES. Despite these limitations, we believe this study still makes a contribution to the literature.

\section{Conclusions}

Our results suggested that in the United States, high EA is associated with a reduced level of perceived stress at work; however, the magnitude of this association depends on the racial and ethnic background of the employee. While highly EA Whites work at low-stress jobs, highly educated AAs and Hispanics experience higher levels of workplace stress. As a result, AAs and Hispanics gain less health benefits from their high EA and employment status.

Author Contributions: S.A.-Conceptualization, analysis, draft, revision, and approval of the final draft. M.B.-Conceptualization, revision, and approval of the final draft.

Funding: Assari and Bazargan are supported by the Center for Medicare and Medicaid Services (CMS) Grant 1H0CMS331621, as well as the NIH Awards 54MD008149, R25 MD007610, 2U54MD007598, and U54 TR001627. Assari is also supported by the NIMHD award 5S21MD000103. The publicly available data set was downloaded from the NHIS website at CDC. The NHIS is funded by the CDC. The content is solely the responsibility of the authors and does not necessarily represent the official view of the funders (NIMHD, NIH, CMS, or CDC).

Conflicts of Interest: The authors declare no conflicts of interest.

\section{References}

1. Assari, S. Parental Educational Attainment and Mental Well-Being of College Students; Diminished Returns of Blacks. Brain Sci. 2018, 8, 193. [CrossRef] [PubMed]

2. Assari, S. Health Disparities due to Diminished Return among Black Americans: Public Policy Solutions. Social Issues Policy Rev. 2018, 12, 112-145. [CrossRef] 
3. Assari, S. Unequal Gain of Equal Resources across Racial Groups. Int. J. Health Policy Manag. 2017, 7, 1-9. [CrossRef] [PubMed]

4. Farmer, M.M.; Ferraro, K.F. Are racial disparities in health conditional on socioeconomic status? Soc. Sci. Med. 2005, 60, 191-204. [CrossRef] [PubMed]

5. Hudson, D.L.; Bullard, K.M.; Neighbors, H.W.; Geronimus, A.T.; Yang, J.; Jackson, J.S. Are benefits conferred with greater socioeconomic position undermined by racial discrimination among African American men? J. Mens. Health 2012, 9, 127-136. [CrossRef] [PubMed]

6. Assari, S. Education Attainment and Obesity Differential Returns Based on Sexual Orientation. Behav. Sci. (Basel) 2019, 9, 16. [CrossRef]

7. Assari, S. Parental Education Attainment and Educational Upward Mobility; Role of Race and Gender. Behav. Sci. (Basel) 2018, 8, 107. [CrossRef]

8. Assari, S. Educational Attainment Better Protects African American Women than African American Men Against Depressive Symptoms and Psychological Distress. Brain. Sci. 2018, 8, 182. [CrossRef]

9. Assari, S. Family Income Reduces Risk of Obesity for White but Not Black Children. Children (Basel) 2018, 5, 73. [CrossRef]

10. Assari, S. Life Expectancy Gain Due to Employment Status Depends on Race, Gender, Education, and Their Intersections. J. Racial Ethn. Health Disparities 2018, 5, 375-386. [CrossRef]

11. Assari, S.; Moghani Lankarani, M. Poverty Status and Childhood Asthma in White and Black Families: National Survey of Children's Health. Healthcare (Basel) 2018, 6, 62. [CrossRef]

12. Assari, S.; Thomas, A.; Caldwell, C.H.; Mincy, R.B. Blacks' Diminished Health Return of Family Structure and Socioeconomic Status; 15 Years of Follow-up of a National Urban Sample of Youth. J. Urban Health 2018, 95, 21-35. [CrossRef] [PubMed]

13. Assari, S.; Farokhnia, M.; Mistry, R. Education Attainment and Alcohol Binge Drinking: Diminished Returns of Hispanics in Los Angeles. Behav. Sci. (Basel) 2019, 9, 9. [CrossRef] [PubMed]

14. Assari, S. High Income Protects Whites but Not African Americans against Risk of Depression. Healthcare (Basel) 2018, 6, 37. [CrossRef]

15. Assari, S.; Mistry, R. Educational Attainment and Smoking Status in a National Sample of American Adults; Evidence for the Blacks' Diminished Return. Int. J. Environ. Res. Public Health 2018, 15, 763. [CrossRef] [PubMed]

16. Assari, S.; Mistry, R.; Caldwell, C.H. Perceived Discrimination and Substance Use among Caribbean Black Youth; Gender Differences. Brain. Sci. 2018, 8, 131. [CrossRef]

17. Assari, S.; Mistry, R.; Caldwell, C.H.; Zimmerman, M.A. Marijuana Use and Depressive Symptoms; Gender Differences in African American Adolescents. Front. Psychol. 2018, 9, 2135. [CrossRef] [PubMed]

18. Assari, S.; Bazargan, M. Unequal Effects of Educational Attainment on Workplace Exposure to Second-Hand Smoke by Race and Ethnicity; Minorities' Diminished Returns in the National Health Interview Survey (NHIS). J. Med. Res. Innov. 2019, 3, e000179. [CrossRef]

19. Assari, S. Blacks' Diminished Return of Education Attainment on Subjective Health; Mediating Effect of Income. Brain Sci. 2018, 8, 176. [CrossRef]

20. Tada, A.; Sugimoto, N.; Sato, K.; Akiyama, T.; Asanoma, M.; Yun, Y.S.; Yamazaki, T.; Tanamoto, K. [Examination of original plant of Jamaica quassia extract, a natural bittering agent, based on composition of the constituents]. Shokuhin Eiseigaku Zasshi 2009, 50, 16-21. [CrossRef]

21. Assari, S. Parental Educational Attainment and Academic Performance of American College Students; Blacks' Diminished Returns. J. Health Econ. Dev. 2019, 1, 21-31. [PubMed]

22. Adams, P.F.; Barnes, P.M.; Vickerie, J.L. Summary health statistics for the U.S. population: National Health Interview Survey, 2007. Vital Health Stat. 10 2008, 238, 1-104. [PubMed]

23. Velez, B.L.; Moradi, B.; Brewster, M.E. Testing the tenets of minority stress theory in workplace contexts. J. Couns. Psychol. 2013, 60, 532-542. [CrossRef] [PubMed]

24. Siegrist, J.; Klein, D.; Voigt, K.H. Linking sociological with physiological data: the model of effort-reward imbalance at work. Acta. Physiol. Scand. Suppl. 1997, 640, 112-116. [PubMed]

25. Kulikowski, K.; Orzechowski, J. All employees need job resources-Testing the Job Demands-Resources Theory among employees with either high or low working memory and fluid intelligence. Med. Pr. 2018, 69, 483-496. [CrossRef] 
26. Bakker, A.B.; Demerouti, E.; Dollard, M.F. How job demands affect partners' experience of exhaustion: Integrating work-family conflict and crossover theory. J. Appl. Psychol. 2008, 93, 901-911. [CrossRef]

27. Mueller, C.W.; Mutran, E.; Boyle, E.H. Age discrimination in earnings in a dual-economy market. Res. Aging 1989, 11, 492-507. [CrossRef]

28. Grow, A.; Van Bavel, J. Assortative mating and the reversal of gender inequality in education in europe: An agent-based model. PLoS ONE 2015, 10, e0127806. [CrossRef]

29. Bowman, P.J. Toward a dual labor-market approach to black-on-black homicide. Public Health Rep. 1980, 95, 555-556.

30. Oldenburg, M.; Jensen, H.J. Stress and Strain among Seafarers Related to the Occupational Groups. Int. J. Environ. Res. Public Health 2019, 16, 1153. [CrossRef]

31. Quick, J.C.; Henderson, D.F. Occupational Stress: Preventing Suffering, Enhancing Wellbeing. Int. J. Environ. Res. Public Health 2016, 13, 459. [CrossRef] [PubMed]

32. Lunau, T.; Siegrist, J.; Dragano, N.; Wahrendorf, M. The association between education and work stress: Does the policy context matter? PLoS ONE 2015, 10, e0121573. [CrossRef] [PubMed]

33. Rodriguez, J.M.; Bound, J.; Geronimus, A.T. US infant mortality and the President's party. Int. J. Epidemiol. 2014, 43, 818-826. [CrossRef] [PubMed]

34. Rodriguez, J.M. The politics hypothesis and racial disparities in infants' health in the United States. SSM Popul Health 2019, 8, 100440. [CrossRef] [PubMed]

35. Rodriguez, J.M. Health disparities, politics, and the maintenance of the status quo: A new theory of inequality. Soc. Sci. Med. 2018, 200, 36-43. [CrossRef] [PubMed]

36. Rodriguez, J.M.; Geronimus, A.T.; Bound, J.; Dorling, D. Black lives matter: Differential mortality and the racial composition of the U.S. electorate, 1970-2004. Soc. Sci. Med. 2015, 136-137, 193-199. [CrossRef] [PubMed]

37. Dragano, N.; Siegrist, J.; Wahrendorf, M. Welfare regimes, labour policies and unhealthy psychosocial working conditions: a comparative study with 9917 older employees from 12 European countries. J. Epidemiol. Community Health 2011, 65, 793-799. [CrossRef] [PubMed]

38. Bambra, C.; Eikemo, T.A. Welfare state regimes, unemployment and health: A comparative study of the relationship between unemployment and self-reported health in 23 European countries. J. Epidemiol. Community Health 2009, 63, 92-98. [CrossRef]

39. Kim, I.H.; Muntaner, C.; Vahid Shahidi, F.; Vives, A.; Vanroelen, C.; Benach, J. Welfare states, flexible employment, and health: A critical review. Health Policy 2012, 104, 99-127. [CrossRef]

40. Assari, S.; Schatten, H.T.; Arias, S.A.; Miller, I.W.; Camargo, C.A.; Boudreaux, E.D. Higher Educational Attainment is Associated with Lower Risk of a Future Suicide Attempt among Non-Hispanic Whites but not Non-Hispanic Blacks. J. Racial Ethn. Health Disparities 2019, 6, 1-10. [CrossRef]

41. Assari, S.; Hani, N. Household Income and Children's Unmet Dental Care Need; Blacks' Diminished Return. Dent. J. (Basel) 2018, 6, 17. [CrossRef] [PubMed]

42. Shervin, A.; Ritesh, M. Diminished Return of Employment on Ever Smoking among Hispanic Whites in Los Angeles. Health Equity 2019, 3, 138-144. [CrossRef]

43. Assari, S.; Lankarani, M.M. Education and Alcohol Consumption among Older Americans; Black-White Differences. Front. Public Health 2016, 4, 67. [CrossRef] [PubMed]

44. Assari, S. Educational Attainment and Exercise Frequency in American Women; Blacks' Diminished Returns. Women Health Bull. 2019, 6, e87413. [CrossRef]

45. Assari, S. Combined Racial and Gender Differences in the Long-Term Predictive Role of Education on Depressive Symptoms and Chronic Medical Conditions. J. Racial Ethn. Health Disparities 2017, 4, 385-396. [CrossRef] [PubMed]

46. Assari, S. The Benefits of Higher Income in Protecting against Chronic Medical Conditions Are Smaller for African Americans than Whites. Healthcare (Basel) 2018, 6, 2. [CrossRef] [PubMed]

47. Assari, S.; Lapeyrouse, L.M.; Neighbors, H.W. Income and Self-Rated Mental Health: Diminished Returns for High Income Black Americans. Behav. Sci. (Basel) 2018, 8, 50. [CrossRef]

48. Assari, S.; Lankarani, M.M. Race and Urbanity Alter the Protective Effect of Education but not Income on Mortality. Front. Public Health 2016, 4, 100. [CrossRef]

49. Assari, S.; Caldwell, C.H.; Zimmerman, M.A. Family Structure and Subsequent Anxiety Symptoms; Minorities' Diminished Return. Brain. Sci. 2018, 8, 97. [CrossRef] 
50. Ruiz, M.; Goldblatt, P.; Morrison, J.; Porta, D.; Forastiere, F.; Hryhorczuk, D.; Antipkin, Y.; Saurel-Cubizolles, M.J.; Lioret, S.; Vrijheid, M.; et al. Impact of Low Maternal Education on Early Childhood Overweight and Obesity in Europe. Paediatr. Perinat. Epidemiol. 2016, 30, 274-284. [CrossRef]

51. Marmot, M.G.; Bell, R. Action on health disparities in the United States: commission on social determinants of health. JAMA 2009, 301, 1169-1171. [CrossRef] [PubMed]

52. Marmot, M. Social determinants of health inequalities. Lancet 2005, 365, 1099-1104. [CrossRef]

53. Marmot, M. The Status Syndrome: How Social Standing Affects Our Health and Longevity; Owl Books: Toronto, ON, Canada, 2004.

54. Marmot, M. Economic and social determinants of disease. Bull. World Health Organ. 2001, 79, 988-989. [PubMed]

(C) 2019 by the authors. Licensee MDPI, Basel, Switzerland. This article is an open access article distributed under the terms and conditions of the Creative Commons Attribution (CC BY) license (http://creativecommons.org/licenses/by/4.0/). 